\title{
MARRIAGE IN THE NEW MILLENNIUM: IS THERE A PLACE FOR SOCIAL COGNITION IN MARITAL RESEARCH?
}

\author{
Frank D. Fincham \\ State University of New York at Buffalo \\ Steven R. H. Beach \\ University of Georgia
}

\begin{abstract}
Although the interchange between clinical and social psychological research has been fruitful in the study of cognition in marriage, it has recently waned. This article therefore illustrates the value of continued interplay between developments in the social cognition and marital literatures, focusing on the role of context in understanding marriage. Several studies show how construct accessibility, including the construct of marital quality, provides a context that influences judgments of partner behavior, the stability of marital quality, and observed marital behavior. The effects of context on reported marital quality are also examined. Finally, an expanded interplay between social cognition and marital research is illustrated using as examples self-evaluation maintenance processes and goals analysis. It is concluded that the social cognitive perspective has the potential to provide a different understanding of marital cognition in the new millenium.
\end{abstract}

KEY WORDS - construct accessibility - marital behavior • relationship quality

The advent of the new millenium prompts most of us to wonder about our personal and professional worlds in the next century. What advances will

\footnotetext{
The preparation of this manuscript was supported by a Social Science Research Fellowship from the Nuffield Foundation; a grant from the Economic and Social Research awarded to Frank Fincham; by a grant from the National Science Foundation award to Steven R. H. Beach; and by a grant from the Templeton Foundation awarded to Frank Fincham and Steven R. H. Beach. Correspondence concerning this article should be addressed to Frank Fincham, Department of Psychology, Park Hall, SUNY at Buffalo, Buffalo, NY 14260-4110, USA [E-mail: fincham@buffalo.edu].
} Thousand Oaks, CA and New Delhi), Vol. 16(6): 685-704. [0265-4075 (199912) 16:6; 010447] 
the 21 st century bring to our understanding of marriage and family? Although futurologists may be able to provide a detailed answer to this question, we set ourselves a more modest goal in this paper — to illustrate the value of greater interchange between the social cognition and marital research literatures in psychology. The theme underlying this illustration is the role of context (particularly the spouse's immediate, psychological context) in understanding marriage. We begin by briefly reflecting on the emergence of research on marital cognition. This provides a context for documenting differing views of such research and leads us to offer illustrations to support our more general thesis that social cognition has the potential to provide a different understanding of marital cognition in the new millenium.

\section{Looking back to look ahead}

Systematic research on close relationships in psychology is found in clinical, social, and, more recently, developmental psychology literatures. However, the relationships studied and approaches to their study have led to important differences across subdisciplines. In this section, we address an emerging discontinuity across social and clinical psychology in the study of cognition in close relationships.

When systematic research on marriage in psychology emerged during the 1970s, it reflected the applied concerns of clinical psychologists and focused on identifying behavioral correlates of marital distress that could be targeted for change in therapy. Yet a seminal study that was the prototype for this research had accorded 'organized structures or images of the self and others' (Rauch, Barry, Hertel, \& Swain, 1974, p. 43) a central role in understanding behavior. In the 1980s this legacy was reclaimed and research on marital cognition flourished in clinical psychology. This work was closely integrated with developments in social psychology.

By the late 1970s, social psychological research on relationships was moving beyond investigating interpersonal attraction to study extant relationships (Fletcher \& Fitness, 1996). One important and lasting influence in this transition was the use of interdependence and social exchange theories, which can be viewed in terms of judgments partners make in relationships and, therefore, are critical to understanding marital cognition. Although these theoretical perspectives influenced the thinking of marital researchers, the emergence of a marital cognition literature in the clinical domain awaited a second development.

A second development was the adoption of an attributional framework for investigating close relationships that emphasized the importance of perceived causation, the same perspective that guided marital cognition research published in clinical journals (see Bradbury \& Fincham, 1990; Fletcher \& Fincham, 1991). The interplay between social and clinical research in this area was profound. It quickly led to a new understanding of marital dysfunction that integrated cognitive and contextual processes (e.g., 
Bradbury \& Fincham, 1991) and gave rise to a new generation of well-specified interventions (e.g., Baucom \& Epstein, 1990). In fact, the way partners' construe their marital difficulties and the attributions they make for them continues to be emphasized in newer, acceptance-based intervention techniques (e.g., by providing a new understanding of the couple's problem that allows spouses to exit from mutual blame, Jacobson \& Christensen, 1996, pp. 41-58). Clearly, the explosion of research that emerged from the synergy of clinical and social perspectives on attributions and other cognitive content variables was exciting and had an important impact on the scientific understanding of marriage and the practice of marital therapy. However, in the 1990s, clinical and social investigations of cognition in relationships have begun to diverge. Why?

\section{Current status and attitudes}

Although attribution theory has been extraordinarily useful, it was developed before the social cognitive perspective that now pervades social psychology. This new perspective does not discount the importance of attributions but, rather, views them as one component in a broader, cognitive framework. Social cognition borrows heavily from cognitive psychology and has helped to expand the study of cognition in close relationships to include the investigation of non-conscious cognition.

Perhaps not surprisingly, the social psychological literature contains numerous illustrations of how a social cognitive perspective can inform our understanding of close relationships. These include research on working models of attachment (e.g., Baldwin, Keelan, Fehr, Enns, \& KohRangarajoo, 1996; Shaver, Collins, \& Clark, 1996), prototypes to study interpersonal concepts such as love and relationship satisfaction (e.g., Fehr \& Russell, 1991; Haasebrauck, 1997), representations of the connection between self and close others (e.g., Aron \& Aron, 1996), self-verification processes in close relationships (e.g., Katz \& Beach, 1997), the effects of emotion knowledge and scripts on relationship behavior (e.g., Fitness, 1996), the use of the schema construct to understand information processing in relationships (e.g., Baldwin, 1992), and the role of social cognitive processes in an individual's construction of illusions about the relationship (e.g., Murray, Holmes, \& Griffin, 1996). Similarly, work on transactive memory systems (Hollingshead, 1998; Wegner, 1987) suggests implicit coordination of partners' memory for events, and a strong role for socialcognitive processes in the dyadic construction of reality. It is apparent that social psychologists have expanded their research to include the study of cognitive structure (how people represent information mentally) and cognitive processes (how people operate on information and how mental representations are transformed) in relationships.

In contrast, most marital researchers in clinical psychology have retained their focus on conscious cognitive content (what spouses think). There are good reasons for clinical researchers to retain their interest in cognitive 
content. Standards, assumptions, attributions, and several other cognitive contents have already been shown to be related to a variety of interesting and important marital processes and outcomes (e.g., Baucom, Epstein, Rankin, \& Burnett, 1996; Bradbury, Beach, Fincham, \& Nelson, 1996; for reviews see Fincham, 1994, 1998). But the attribution glue that bound together social and clinical research perspectives on marriage has not been replaced and these two subdisciplinary perspectives on marriage are becoming increasingly isolated from each other. This process is facilitated by an apparent skepticism among marital researchers regarding the utility of contemporary social cognition research, a circumstance that motivates the rapprochement explored in this article.

Consider a recent interchange that occurred on the listserve of a marital research special interest group. Weiss (1996) asked whether completing a widely used marital quality measure, the Dyadic Adjustment Scale, might influence subsequent marital interaction. The question was presumably prompted by a considerable body of work on social cognition, suggesting that making readily available knowledge stored in memory (priming it; in this case, the spouse's evaluation of the marriage) can influence subsequent behavior. This question is of clear methodological importance. If priming of one sort or another influenced marital interactions, this would be an important influence to control in observational research. Likewise, because filling out questionnaires prior to interaction is a relatively common practice, it would be particularly important if this activity influenced subsequent behavior. Yet, the reaction of some clinical marital researchers to this question was to dismiss it along with the entire domain of questions having to do with social cognitive process. Indeed, one response by a well known marital researcher expressed considerable irritation at 'human experimental psychologists ... pointing out implausible but theoretically possible confounds' that 'only a cognitive psychologist with little else to do but criticize clinical phenomena would make a big deal out of.'

But it is no more possible to 'argue away' concerns like the one raised on this listserve than it would be to argue away the concern that correlations between communication and marital satisfaction inventories are inflated because of item overlap or that sample attrition may influence longitudinal research results. What is needed, then, is an experimental demonstration that this particular issue does not represent a problem within marital research. This is critically important for the field, as the basic paradigm used in much marital research entails spouses completing questionnaires and engaging in observed interactions in the same laboratory session.

\section{Social cognition and marriage: Is any partnership viable?}

Dismissing the importance of social cognitive effects for marital research may be analogous to engineers wondering if they can safely ignore the increase in mass that accompanies acceleration. For some applications, it 
may be safe to do so (e.g., at ordinary terrestrial speeds), but for others it may be a critical omission (e.g., as objects approach the speed of light). Similarly, activation of a spouse's stored knowledge may be more or less critical depending on the context.

What do data show with regard to a possible questionnaire completion - behavior interaction? We are not aware of any published data that specifically address the question. Consequently, we conducted a study premised on the assumption that if completing marital quality questionnaires does not influence subsequent judgments of partner behavior, it is unlikely to influence subsequent interaction between spouses. If it does influence such judgments, this would justify the more labor intensive task of examining the relation to observed behavior.

\section{Study 1}

We randomly assigned 100 community couples to one of two experimental conditions. Shortly after their arrival in the laboratory, spouses either completed three measures of marital quality (Marital Adjustment Test (MAT), Locke \& Wallace, 1959; Quality of Marriage Index, Norton, 1983; and a Semantic Differential comprising evaluative, bipolar adjectives about the marriage) or they completed some personality questionnaires about themselves that took an approximately equal amount of time as the marital questionnaires (spouses in this group later completed the MAT). Following this experience, they were asked to evaluate a number of partner behaviors (e.g., "my partner disagrees with something I say', 'my partner offers me a cup of tea but forgets to make it') by marking a line with end points labeled extremely positive and extremely negative. No differences were found on a summated index of responses to nine behaviors (coefficient $\alpha$ : wives $=.72$, husbands $=.69$ ) as a function of the experimental manipulation (personality questionnaires first, mean $=76.2, S D$ $=11.7$; marital questionnaires first, mean $=74.6, S D=11.6)$. Perhaps more important is the possibility that completing marital quality questionnaires alters the relationship between marital quality and ratings of partner behavior. However, the correlation between MAT scores and ratings did not differ by condition $(r=.30$ versus .21$)$.

Accordingly, there may be an empirical basis for suggesting that, within the boundaries of marital satisfaction inventories and judgments of partner behavior (and so probably behavior towards the partner as well), reporting on marital satisfaction does not affect subsequent responses pertaining to the marriage. Does this imply that a prior task will never influence subsequent reactions to partner behavior? Some responses to Weiss' question seemed to imply that marital researchers should assume no effect and turn a blind eye to the possibility of such effects intruding for both laboratorybased and naturally occurring couple interactions. But the influence of activated, prior knowledge on subsequent information processing and behavior (priming effects) is quite ubiquitous and extremely well-documented. It would be very surprising if it were not possible to demonstrate such effects in the marital area. More importantly, it would be surprising if such effects did not eventually lead us to new conceptualizations of marital difficulties and new approaches to marital intervention. To investigate the 
possibility that a more targeted task might have an impact on evaluations of partner behavior, a second study was conducted.

\section{Study 2}

A sample of 95 newlywed couples recruited through marriage license records and advertising participated in this study. All couples engaged in a sentence construction task that asked respondents to underline three of four possible words that can be used to make a sentence (Srull \& Wyer, 1979). However, for half of the sample, 80 percent of the generated sentences were designed to activate the concept of hostility (e.g., 'break arm his leg', 'demean her I him'). The other half of the sample constructed neutral sentences (e.g., 'book the read poem'). Following this task, spouses were asked to imagine their partner performing a variety of behaviors (e.g., 'my spouse telling me I made a mistake') and indicate how hostile they considered the behavior. They also rated the extent to which the word 'hostile' described their spouse.

Ratings of imagined behavior (coefficient $\alpha$ : wives $=.73$, husbands $=.80$ ) were highly consistent. However, as Table 1 shows, the ratings of partner behavior, but not ratings of trait hostility, differed as a function of the hostility manipulation. Spouses exposed to the hostility manipulation rated partner behavior as less hostile, which is consistent with a contrast effect (i.e., stimuli are not seen as similar or belonging to the category of information previously primed - an assimilation effect - but as quite different from or the opposite of the primed category - a contrast effect). The mechanism producing this effect was not investigated (a simple explanation is that respondents used the exemplars of hostility in the priming condition as standards; thus, use of very hostile exemplars made the targeted partner's behaviors appear relatively benign in comparison) but it is not unusual to obtain contrast effects (e.g., Herr, Sherman, \& Fazio, 1983; Schwarz \& Bless, 1992). The important point here is to note that such results suggest that marital researchers can not afford to ignore the effect of cognitive process variables. Priming the construct of hostility changed responses to particular partner behaviors. It is likely that a variety of relatively simple contrast and assimilation effects change reactions to the partner and subsequent interaction with the partner.

\section{Perhaps a limited partnership?}

The findings of Study 2 suggest that accessibility or priming effects may be

TABLE 1

Means scores and standard deviations (in parentheses) for ratings of spouse behavior and trait hostility as a function of hostility manipulation

\begin{tabular}{lcc}
\hline & \multicolumn{2}{c}{ Experimental condition } \\
\cline { 2 - 3 } & Hostility exposure & No hostility exposure \\
\hline Husbands & $23.2(10.7)$ & $27.5(12.1)$ \\
$\quad$ Spouse behavior & $9.0(2.3)$ & $9.6(2.9)$ \\
Trait hostility & & \\
Wives & $28.9(10.8)$ & $33.1(9.7)$ \\
$\quad$ Spouse behavior & $8.0(3.0)$ & $8.3(3.0)$ \\
$\quad$ Trait hostility & \\
\hline
\end{tabular}


complex. Indeed, when priming manipulations are too obvious, they may produce contrast effects or may not work at all. In fact, the impact of priming is influenced by a variety of factors, including its recency, frequency, blatancy, awareness of the priming, exact relation between primed and target materials, and so on (see Higgins, 1996). The 'obviousness' of our manipulation in Study 1 might therefore account for the failure to show that activating spouses' marital quality influenced subsequent judgments. In addition, it may be difficult to show priming effects in contexts that already make the primed construct accessible. The couple context and/or questions about the partner/marriage may automatically activate the construct of marital quality, making it chronically accessible in such contexts so that additional priming of the construct may have little impact on marital ratings or marital behavior.

Clinical observation appears to support the chronic accessibility hypothesis for marital quality. According to the sentiment override hypothesis, spouses respond to their partner, question about the marriage, and so on according to their dominant sentiment about the marriage, rather than on the basis of the particular partner behavior or questions to which they have been exposed (Weiss, 1980). Consistent with the pervasive accessibility assumption underlying this hypothesis is an interesting finding in the social psychology literature. Schwarz, Strack, and Mai (1991) found that when respondents were asked about their life satisfaction before their marital satisfaction, the correlation between the two responses was .32. However, when the marital satisfaction question occurred first, the correlation increased to .67. One way to view these correlations is in terms of the extent to which making the first judgment supplied information relevant to the second. The life satisfaction judgment may have supplied little information because spouses have ready access to their marital satisfaction and so it is not easily influenced. In contrast, marital satisfaction may be viewed as a relevant component of life satisfaction, so that when marital satisfaction is primed, life satisfaction judgments are assimilated to the prime. Below, we return to these considerations in our discussion of context effects on judgments of marital quality. For now, it is sufficient to note that priming marital quality may influence subsequent responses under at least some circumstances.

In view of these considerations, acceptance of limited accessibility effects for marital quality would be premature, especially in view of the sparse data available and the need for more sophisticated study of marital quality from a social cognitive perspective. The next section of the paper therefore describes attempts to demonstrate the role of construct accessibility in understanding marriage. The illustrations are not offered as the only or the best ways to rekindle the synergy between social and clinical research on cognition in close relationships evident in the 1980s; rather, they are intended only to indicate the potential fruitfulness of such a partnership to the field of personal relationships. 


\section{Social cognition and marriage: Illustrating a viable partnership}

The influence of activated concepts from stored knowledge on subsequent responses is so ubiquitous in social cognition research that it would be surprising if such effects did not exist in regard to a spouse's mental representation of his or her marital quality. As noted, however, manipulating the accessibility of marital quality to show effects on subsequent responses may be more complex than it first appears and, in any event, may not speak directly to concerns about clinical relevance outside the laboratory. As a consequence, we adopted a different approach to the study of accessibility effects that focuses on individual differences and is informed by a social cognitive perspective on attitudes.

Influenced by research and theory on memory as a network of associated elements, Fazio $(1990,1995)$ conceptualizes an attitude as a specific association between an attitude object and its evaluation. This association can vary in strength across attitude objects; for some (e.g., 'snake' for snake phobics), their mere mention or presentation activates an evaluation automatically, whereas for others (e.g., 'spoon') an evaluative association is weak or non-existent. Similarly, the strength of any given attitude can differ across individuals. In any event, the strength of this association is critical as it determines whether the attitude is activated when the person acts in relation to the attitude object. When the attitude is highly accessible, it is likely to affect subsequent information processing and behavior.

This conception of attitudes can be profitably integrated with attempts to reconceptualize marital quality in terms of overall, evaluative judgments (e.g., Fincham \& Bradbury, 1987; Huston, McHale, \& Crouther, 1986; Norton, 1983), a reconceptualization that is clinically relevant as it reflects the final common pathway through which marital dysfunction is expressed (Jacobson, 1985). According to such an integrated perspective, spouses will differ in the ease with which an evaluation is activated when exposed to the spouse or to marriage-relevant stimuli and the importance of individual differences in concept accessibility is well-documented (Markus \& Smith, 1981). Thus, even if marital quality is chronically accessible to all spouses, individual differences in accessibility may still exist and influence responses to the partner/marriage. Such differences imply that the influence of spouse sentiment is likely to vary as a function of its accessibility. This can be tested by examining whether associations between marital quality and its documented correlates (e.g., spouse judgments and behavior) are higher for spouses with more accessible attitudes (sentiment) than for spouses with relatively less accessible attitudes. Are there any data to support this prediction?

\section{Study 3}

The strength of attitude object-evaluation associations has been operationalized as the temporal latency of an evaluative response to the attitude object. We used this operationalization to index the accessibility of spouses' evaluative judgments using two procedures (see Fincham, Garnier, Gano-Phillips, \& 
Osborne, 1995). The first involved a binary choice (positive-negative) task in which various items, including marriage relevant items (e.g., 'your wife'), served as stimuli. The second concerned answers to questions about the marriage (e.g., 'The relationship I have with my husband is satisfying') given on 5-point rating scales (ranging from strongly disagree to strongly agree). In each case, response latencies were timed for 92 couples recruited from the community. Latencies were adjusted for differences in baseline speed of responding, and fast and slow groups were formed that did not differ in marital quality (e.g., for the rating task, groups were formed at each response point on the scale).

For both husbands and wives, fast responders showed a significantly higher correlation between MAT scores and judgments of partner contributions to negative marital events $(-.52,-.51$, for husbands and wives, respectively) than slow responders $(-.09, .24$ for husbands and wives, respectively). For husbands, accessibility also moderated the relation between MAT scores and anticipated wife behavior in an upcoming interaction (correlations for fast group $=.70$, slow group $=.37$ ). The same results were found when using latencies derived from the rating scale task. These results suggest that naturally occurring individual differences in accessibility may be important for understanding the correlates of marital quality. Left unanswered, however, is the question of whether such effects extend beyond simple judgment tasks?

\section{Study 4}

To address this concern, we first examined whether accessibility might be related to the stability of marital quality. It can be hypothesized that spouses whose marital quality is highly accessible are likely to behave towards their partner in a manner more consistent with their marital quality than spouses whose marital quality is not as highly accessible. Consistency of spouse behavior should lead to greater stability in partners' reports of marital quality over time. Using the choice reaction time task in the last wave of a longitudinal study, we were able to address this question by assuming that the reaction-time measure also reflected accessibility of evaluative judgments in earlier waves of data collection. Adjusting for differences in baseline speed of responding across individuals, response latencies were used to form two accessibility groups that did not differ in marital quality. Within each group, we then computed correlations between the partner's current MAT scores, scores collected 12 months earlier, and collected 18 months earlier. Table 2 shows the correlations obtained for the two groups. For husbands and wives, corresponding testretest correlations for partner MAT scores differed significantly across the two groups. All six correlation differences were in the predicted direction $\left(\chi^{2}(1, n=6)=6, p<.02\right)$. These results are consistent with the possibility that accessibility of a spouse's evaluation of the partner/marriage influences his or her behavior towards the partner, which, in turn, influences partner reports of marital quality. However, they do not demonstrate a link between accessibility and marital behavior. This question is therefore addressed in the next study.

\section{Study 5}

Spouses in 56 community couples completed the binary choice reaction time task, the MAT, and a standard 12-minute problem-solving discussion during the course of a laboratory session. Each 3-minute segment of the problem-solving discussion was rated by a trained coder for the amount of support (listening 
TABLE 2

Test-retest correlations among partner's Marital Adjustment Test (MAT) scores over time as a function of spouse being in High-accessibility (above diagonal) or Low-accessibility (below diagonal) group

\begin{tabular}{llll}
\hline & $\mathbf{1}$ & $\mathbf{2}$ & $\mathbf{3}$ \\
\hline 1. Wife current MAT & & $.75^{*}$ & $.67^{*}$ \\
2. Wife MAT 12 months earlier & .46 & & .83 \\
3. Wife MAT 18 months earlier & .33 & .79 & \\
1. Husband current MAT & & .87 & $.83^{*}$ \\
2. Husband MAT 12 months earlier & .78 & & $.86^{*}$ \\
3. Husband MAT 18 months earlier & .58 & .62 & \\
\hline
\end{tabular}

* Indicates significantly higher correlation $(p<.05)$ compared with corresponding correlation below diagonal.

skills, reinforcing partner's behaviors) and the amount of conflict (tension, hostility, negative affect) shown by each spouse on a 9-point rating scale (see Julien, Markman, Lindahl, Johnson, \& Van Widenfelt, 1989). The dimensions were selected because they represent the two major forms of behavior investigated in the marital interaction literature. Inter-rater reliability in coding was high (support: wife $=.82$, husband $=.85$; conflict: wife $=.96$, husband $=$ $.81)$.

Again, using appropriate controls, we formed accessibility groups for husbands and wives. Table 3 shows the correlations between marital quality and coded behaviors in these groups. Six of the eight correlations between marital quality and behavior were significant in the high accessibility group and all were non-significant in the lower accessibility group (with only 28 spouses in each group, there was too little power to meaningfully test for differences in the magnitude of correlations between groups). The likelihood of all the differences being in the predicted direction differed significantly from chance $\left(\chi^{2}(1\right.$, $n=8)=8, p<.01)$. Because interactional behavior is often mistakenly attributed to a single interactant (the pseudounilaterality error, Duncan, Kanki,

TABLE 3

Correlations between Marital Adjustment Test (MAT) scores and behavior for high and low accessibility groups

\begin{tabular}{lccccc}
\hline \multirow{2}{*}{ Group } & \multicolumn{2}{c}{ Conflict behavior } & & \multicolumn{2}{c}{ Support behavior } \\
& Husbands & Wives & & Husbands & Wives \\
\hline Husbands & $-.34^{*}$ & $-.42^{*}$ & & $.37^{*}$ & $.36^{*}$ \\
$\quad$ High accessible & -.09 & .00 & & -.19 & .24 \\
$\quad$ Low accessible & $-.36^{*}$ & -.33 & & .32 & $.42^{*}$ \\
Wives & .02 & .12 & & -.01 & .24 \\
$\quad$ High accessible & & & & \\
$\quad$ Low accessible & & &
\end{tabular}

$* p<.05$, one-tailed. 
Mokros, \& Fiske, 1984), the data were also examined at the couple level by combining scores for husbands and wives on all variables. Marital quality was significantly $(p<.05)$ related to support $(r=.44)$ and conflict $(r=-.45)$ in the more accessible group and unrelated to behavior in the less accessible group $(r \mathrm{~s}$ $=.00$ and -.01 , respectively). Moreover, the significant difference in correlations between the support and conflict behaviors across groups $(-.86$ versus $-.56, z=2.1, p<.05$ ), despite low power to detect such differences, raises the possibility that accessibility of marital quality may have a general moderating influence on associations between marital behaviors, thereby influencing structural properties of marital interactions. If so, accessibility of marital quality may prove essential in our attempts to describe both marital interaction processes and decipher interaction patterns that forecast longitudinal change in satisfaction. In any event, it appears that accessibility is indeed related to marital behavior.

In sum, the studies described illustrate links between construct accessibility and spouse judgments, the temporal stability of partner marital quality, and behavior towards the partner. Our decision to illustrate these links in relation to the construct of marital quality was not accidental, but reflects the fact that this construct is the most frequently studied in the marital literature (Glenn, 1990) and has resulted in a vast literature on the correlates of marital quality. An important implication of our work on the moderating role of marital quality accessibility is that this literature needs to be reworked. Previously non-significant correlations between marital quality and other constructs may turn out to be significant, at least for spouses whose marital quality is highly accessible, and some correlates of marital quality may prove to be more important than previously thought. In a similar vein, the sentiment override hypothesis may only apply when accessibility is high. The incorporation of accessibility or associative strength into research on marital quality and its correlates is analogous to the refinement of a diagnostic category in a psychiatric nosology into several subcategories. It is not that the original broad category (or set of correlates) is wrong, but rather that it is crude.

In the present context the most important observation to be made about this work is that it is merely one example of a potentially rich synergy between social cognition and marital research. In the next section of the paper, we provide other examples that extend beyond the study of accessibility of marital quality. Before doing so, it remains to note that our illustrations were driven by the question posted on the listserve and only considered how accessibility of marital evaluations might be important for understanding marriage. Addressing this question is fundamental to the basic paradigm used in the collection of marital data where spouses complete questionnaires and engage in interactions. But just as completing marital quality questionnaires raised concerns about responses on subsequent tasks, it is possible that responses on marital quality questionnaires might themselves be influenced by prior events and/or the context in which they are completed. We now turn to explore this possibility. 


\section{Understanding context effects in the assessment of relationship quality}

Context can have several referents and two are discussed in this section. The first is the life events that couples experience that create a context within which their relationship exists. The second is the proximal events that occur during data collection that provide an immediate context in which responses are obtained. Each is discussed in turn.

Although negative life events adversely influence marital interaction (e.g., Bolger, Delongis, Kessler, \& Schilling, 1989; Repetti, 1989) and marital outcomes (Cohan \& Bradbury, 1997; Lavee, McCubbin, \& Olson, 1987), little attention has been given to the way in which couples respond to such events or to their possible effect on marital quality. At the same time, understanding the way in which couples adapt to life events is likely to be crucial for understanding longitudinal change in marital quality, and so addresses a question of pivotal interest to marital researchers (Karney \& Bradbury, 1995). From the standpoint of the social cognition literature, life events can be viewed as contexts that create the potential for assimilation and contrast effects in judgments of marital quality. Accordingly, Tesser and Beach (1998) investigated whether such effects could account for the relationship between life events and relationship satisfaction. Their work was informed by common place findings in the experimental literature on social cognition that show that people both allow context to influence their judgments (assimilation effect) and discount the effects of context when it is both noticed and considered irrelevant to their judgment (contrast effect). But when do people notice a contextual factor as irrelevant? Apparently when it is made salient (e.g., Schwarz \& Clore, 1983) or when it is so blatant as to be obvious (Kubovy, 1977; for a review, see Higgins, 1996). Tesser and Beach (1998) reasoned that similar effects might be found for judgments of relationship satisfaction if the context examined involved ongoing life events.

These investigators suggested that when there are few negative life events (NLEs), or their impact or perceived importance is low, their potential influence on judgments of the partner would not be as obvious. However, when there are many/severe NLEs they should become a blatant or salient context that potentially influences ratings of the partner and can be recognized as an 'irrelevant' influence on partner evaluation. Specifically, when there are few negative events, context should color the evaluation of the partner but, at higher levels of NLEs, there should be evidence of discounting. Tesser and Beach (1998) therefore predicted that, up to a point, with increasing NLEs, judgments of one's intimate relationships would become more negative. However, at some point, NLEs would become sufficiently salient to be discounted, leading to a significant 'jump' toward positivity in one's judgment of relationship quality.

These hypotheses were explored in marital and parenting relationships. Three studies and a mini-meta analysis revealed that, as negative life events increased, judgments of close relationships (including MAT scores) gradually became less favorable, jumped back toward positivity, and then, again, 
gradually became less favorable. The same methods of analysis revealed a relationship between negative life events and negative affect with no evidence of significant discontinuities. In addition, interesting properties of the point of discontinuity were observed, suggesting that it represents a point of openness to the partner and a point at which interactions with the partner may be particularly consequential.

Thus, a social cognitive perspective suggests both non-intuitive relationships between negative life events and marital satisfaction (e.g., an increase in negative life events can produce improved marital satisfaction), and has interesting implications for social support in marriage (e.g., self-reported social support may be most positively related to individual outcomes for the mid-range of negative life events). The Tesser and Beach (1998) paper therefore illustrates the potential for the social cognitive perspective to highlight new directions for marital research.

Is the immediate context in which marital quality is assessed similarly related to spouse reports of marital quality? In addition to the arguments offered earlier in this article, the high temporal stability of marital quality scores suggests that they are not easily influenced by the immediate context in which they are obtained. However, there is evidence that reported relationship quality does vary as a function of fluctuations in mood.

Forgas, Levinger, and Moylan (1994) assessed relationship quality after a naturally occurring mood manipulation (attending a happy or sad movie) and after a mood manipulation in the laboratory. In both studies people evaluated their relationships more negatively when in a sad mood than in a happy mood, which shows assimilation effects for reported relationship evaluation. However, as noted earlier, it is likely that contrast effects could also be obtained if the mood manipulation were made more salient. Unfortunately, the marital status of the participants was not recorded and non-standard measures of relationship quality were used. Thus, whether such mood effects are found for spouses using the kinds of inventories typically employed in the marital literature, and the circumstances under which fluctuations in mood result in assimilation or contrast effects, remains unknown. Should such immediate context effects occur it would then be important to investigate their possible interaction with the more stable relationship context provided by couples' life events. The important point for our current purposes is that the Forgas et al. (1994) study underscores the potential of immediate context to influence judgments of relationship quality.

In sum, it does not appear that reported relationship quality is immune to contextual influences. Rather, under the right circumstances judgments of marital quality are likely to be assimilated or contrasted with contextual factors. Considering the evidence presented thus far, the issue is no longer whether social-cognitive processes are related to marital processes, but whether we can get a clearer picture of how such processes play themselves out in a marital context and how we might harness them under at least some circumstances. Accordingly, a social cognitive framework may prove indispensable to the development of more powerful theoretical models of 
marital functioning. We therefore turn to consider more broadly the integration of social cognition and marital literatures.

\section{Social cognition and marriage: Expanding the partnership}

In expanding our consideration of the marriage-social cognition partnership, we retain a focus on spouse behavior, supplementing earlier reported findings, to show that social cognitive processes are reliably related to a clinically important variable that has played a central role in marital research and therapy. We offer two examples to illustrate the potentially rich synergy between social cognition and marital literatures. One example highlights ways in which judgments about the self are influenced by contrast (comparison) and assimilation (basking in reflected glory) to the behavior of close others. Drawing on self-evaluation maintenance (SEM) theory, this example draws attention to performance factors in close relationships and suggests that social contrast and assimilation effects can influence a variety of relationship processes, including couple behaviors. The second example draws from the even broader literature on self-regulation and highlights ways in which self-regulatory goals might be primed, creating the potential for profound alterations in attention and the organization of interpersonal behavior.

\section{Self-evaluation maintenance in spouses}

Working well together is an important aspect of a successful marriage and is often assessed in measures of marital quality. It suggests coordination of effort that likely requires each spouse to develop unique strengths relative to the partner. The infrastructure supporting the development of performance niches by each partner within the relationship has been termed the couple's 'performance ecology' (Beach, Tesser, Mendolia, Crelia, Whitaker, \& Fincham, 1996). An important aspect of this 'performance ecology' is the self-evaluation maintenance (SEM) process outlined by Tesser (1988), and further elaborated in the extended SEM model by Beach and Tesser (1995). What are the implications of a couple's performance ecology for understanding the partners' behavior?

One simple implication of applying SEM theory to marriage is that poor performance relative to the spouse in high self-relevant areas should have a larger negative effect on the couple than poorer performance in low selfrelevant areas. Thus spouses who are outperformed in an area of high selfrelevance may feel badly (Beach et al., 1998). If unable to discount these negative feelings by recognizing their source, or to counteract them by engaging in subtle adjustments (e.g., changing relevance to self, distorting relative performance), they may act on them, precipitating a negative couple interaction. Manipulating SEM variables therefore provides a way to examine both assimilation of marital behavior to a subtle priming manipulation (e.g., negative comparison with the partner), and underscores the ways in which such priming effects might become translated into 
longer-term changes in level of marital adjustment through self-sustaining behavioral processes. We therefore examined whether SEM manipulations influenced couple behavior.

\section{Study 6}

Forty-eight couples were recruited from the community to explore the hypothesis outlined in the last paragraph. Couples completed a computer administered 'trivial pursuit' task following which they were exposed to one of two sets of feedback: the partner was told that he or she had been outperformed by the spouse in an area low in importance to the self ('positive reflection' condition) or in an area high in importance to the self ('negative comparison' condition). Within couples, spouses were randomly assigned to be either the person who was outperformed or the person who outperformed his or her partner. Following this experience, partners engaged in a discussion of how they met and of their early years of marriage The discussion was rated by three observers (reliability $=.88$ ) and its overall positiveness was examined.

With the potential confounding influence of depressive symptoms and marital quality statistically controlled, couples in the negative comparison condition (being outperformed in an area important to the self) were significantly less positive in their interactions than couples in the positive reflection condition (being outperformed in an area unimportant to the self). This finding is particularly relevant as reminiscence tasks, like the one used in the study, are quite commonly recommended by marital therapists to induce a positively valenced tone into the first marital therapy session (e.g., Jacobson \& Margolin, 1979; Stuart, 1980), and are sometimes used in experimental work to induce a positive, collaborative set before allowing couples to go home (Gottman, 1994). However, it was possible to influence the hedonic tone of this task by inducing negative social-comparison rather than positive reflection prior to having the couple begin the interaction.

The potential importance of such assimilation effects on marital behavior has also been examined in the context of problem-solving discussions with similar effect (O'Mahen, Beach, \& Tesser, in press). In addition, the SEM model has been used to study spouses' activity level in regard to a variety of daily activities, tendency to distort partner needs, marital decision making, and self-reported affective reactions (Beach \& Tesser, 1995; Beach et al., $1996,1998)$. In each case, the results point to potentially important relationship effects that may result from differing levels of threat to self-evaluation. Consistent with our current theme, each example also serves to highlight assimilation and contrast effects linking the partner's behavior to feelings about the self and ultimately to evaluation of the partner.

\section{Goal analysis}

There has been considerable work within the social cognitive framework on 'goals' as an organizing framework and Higgins (1997) provides an important review of the goals literature. Among other things, he points to substantial evidence that the systems underlying approach to pleasurable outcomes and those underlying avoidance of negative outcomes appear to be distinct (cf. Carver \& Scheier, 1999; Gray, 1987). This distinction under- 
scores a recent reconceptualization of marital quality in terms of distinct positive and negative dimensions (see Fincham \& Linfield, 1997), and also the potential to differentially prime positive and negative dimensions of marriage (Fincham, Beach, \& Kemp-Fincham, 1997). As noted by Higgins (1997), successful efforts to differentially prime approach (promotion goals) and avoidance (prevention) goals should influence both attentional and decision-making processes. Applied to the marital area, such distinctions suggest the potential to better understand and influence attention to positive versus negative partner behavior, and to better understand choices about conflict engagement and conflict avoidance in the context of marital disagreement.

Fincham and Beach (1999) examine conflict engagement and avoidance in detail and outline more broadly the implications of a goal theoretic framework for understanding marital behavior, particularly conflict behavior. Importantly, this goal analytic framework is continuous with the developments in the social cognition literature described in this article (see Austin \& Vancouver, 1996; Gollwitzer \& Bargh, 1996), and suggests additional avenues forward for marital research and intervention. In particular, goal constructs and goal processes appear critical in understanding the means by which pro-relationship intentions prior to an interaction with a partner may be transformed into 'defensive' and relationship-defeating patterns of interaction once a discussion gets underway. Consider, for example, a spouse who has good intentions to change a destructive pattern of interaction, yet finds him or herself endlessly repeating it. This may be among the most common and frustrating of clinical problems. The difficulty it poses for clinical intervention suggests the potential utility of a framework that can account for intention-behavior discrepancies. A goal perspective may be able to do so by suggesting that the problem behavior represents an 'emergent' goal activated by a particular relationship context. In other words, the good intentions may represent salient goals so long as the avoidance system is quiescent, but they are quickly replaced when the defensive-avoidance system is activated and the emergent goal of protecting self-esteem comes into play.

In the marital domain, it seems likely that defensive goals reflect a combination of approach and avoidance goals, rendering them particularly stable (Carver \& Scheier, 1999) and particularly well-suited to displacing other approach goals once the avoidance system is activated. For example, the goal of avoiding feeling stupid or 'small' might be combined with an approach goal of 'restoring equity'. If such a goal structure were activated by the partner's negative behavior, a powerful motivation to belittle the partner could be set off by a relatively minor criticism. Even if the misbehaving spouse knew the self-defeating nature of his or her behavior, it might rattle off automatically under the control of the defensive goal system. Likewise, if the 'defensive behavior' of choice by a given partner was stone-walling, negative mind reading, or physical violence, one could see similarly destructive patterns involving these topographies (for further analysis, see Fincham \& Beach, 1999). 
It appears then that a goal theoretic perspective has the potential to capture much of the social-cognition literature and organize it in a way that is intuitive and useful from the standpoint of understanding marital discord and for guiding marital intervention. At the same time, considerable work will be required for this framework to reach its potential in the marital area. If our goal for the next century is to produce more powerful theories that can better guide intervention and prevention, then now is the time to engage the social cognition literature and apply it to marital phenomena. The goal theoretic perspective may be particularly helpful in this regard.

\section{Coda}

It would be misleading if we failed to note that these two examples are not the only or best ways to reinvigorate the interchange between social and clinical literatures on close relationships. As noted earlier, several other promising points of contact exist. Thus, notwithstanding our focus on accessibility, assimilation, and contrast effects, there is considerable potential for collaboration between social cognition researchers and marital researchers to progress on many fronts.

\section{Conclusion}

In this article, we have outlined a program of research that attempts to illustrate the potential contribution of new developments in social cognition to understanding marriage. We did so in the belief that it is time to renew the vows that once joined social and clinical research in a mutually beneficial marriage. The earlier relationship was based on reciprocal respect for the contribution and expertise that each partner brought to the exploration of complex human problems in relating. If we are able to foster the re-emergence of this mutually enriching relationship, the 21 st century may bring dramatic advances in our conceptualization of marriage, our research findings, and our ability to intervene effectively to help persons dealing with marital and family problems

\section{REFERENCES}

Aron, A., \& Aron, E. N. (1996). Self and self-expansion in relationships. In G. J. O. Fletcher \& J. Fitness (Eds.), Knowledge structures in close relationships (pp. 325-344). Mahwah, NJ: Erlbaum.

Austin J. T., \& Vancouver J. B. (1996). Goal constructs in psychology: Structure, process, and content. Psychological Bulletin, 120, 338-375.

Baldwin, M. W. (1992). Relational schemas and the processing of social information. Psychological Bulletin, 112, 461-484.

Baldwin, M. W., Keelan, J. P. R., Fehr, B., Enns, V., \& Koh-Rangarajoo, E. (1996). Social cognitive conceptualization of attachment working models: Availability and accessibility effects. Journal of Personality and Social Psychology, 71, 94-106.

Baucom, D. H., \& Epstein, N. (1990). Cognitive-behavioral marital therapy. New York: Brunner/Mazel. 
Baucom, D. H., Epstein, N., Rankin, L. A., \& Burnett, C. K. (1996). Assessing relationship standards: The Inventory of Specific Relationship Beliefs. Journal of Family Psychology, $10,72-88$.

Beach, S. R. H., Tesser, A. (1995). Self-esteem and the extended self-evaluation model: The self in social context. In M. Kernis (Ed.), Efficacy, agency, and self-esteem (pp. 145-170). New York: Plenum.

Beach, S. R. H., Tesser, A., Fincham, F. D., Jones, D. J., Johnson, D., Whitaker, D. J. (1998). Pleasure and pain in doing well together: An investigation of performance related affect in close relationships. Journal of Personality and Social Psychology, 74, 923-938.

Beach, S. R. H., Tesser, A., Mendolia, M., Crelia, R., Whitaker, D. G., Fincham, F. D. (1996). Self-evaluation maintenance in marriage: Toward a performance ecology of the marital relationship. Journal of Family Psychology, 10, 379-396.

Bolger, N., Delongis, A., Kessler, R. C., \& Schilling, E. (1989). The effects of daily stress on negative mood. Journal of Personality and Social Psychology, 57, 808-818.

Bradbury, T. B., Beach, S. R. H., Fincham, F. D., \& Nelson, G. M. (1996). Attributions and behavior in functional and dysfunctional marriages. Journal of Consulting and Clinical Psychology, 64, 569-576.

Bradbury, T. N., \& Fincham, F. D. (1990). Attributions in marriage: Review and critique. Psychological Bulletin, 107, 3-33.

Bradbury, T. N., \& Fincham, F. D. (1991). A contextual model for advancing the study of marital interaction. In G. J. Fletcher \& F. D. Fincham (Eds.), Cognition in close relationships (pp. 127-147). Hillsdale, NJ: Erlbaum.

Carver, C. S., \& Scheier, M. F. (1999). Theme and issues in the self-regulation of behavior. In R. S. Wyer (Ed.), Perspectives on behavioral self-regulation (Advances in social cognition Vol 12) (pp. 1-106). Mahwah, NJ: Erlbaum.

Cohan, C. L., \& Bradbury T. N. (1997). Negative life events, marital interaction, and the longitudinal course of newlywed marriage. Journal of Personality and Social Psychology, $73,114-128$.

Duncan, S., Kanki, B. G., Mokros, H., \& Fiske, D. W. (1984). Pseudounilaterality, simple-rate variables, and other ills to which interaction research is heir. Journal of Personality and Social Psychology, 46, 1335-1348.

Fazio, R. H. (1990). Multiple processes by which attitudes guide behavior: The MODE model as an integrative framework. In M. P. Zanna (Ed.), Advances in experimental social psychology (Vol. 11, pp. 74-97). Newbury Park, CA: Sage.

Fazio, R. H. (1995). Attitudes as object-evaluation associations: Determinants, consequences, and correlates of attitude accessibility. In R. E. Petty \& J. A. Krosnick (Eds.), Attitude strength: Antecedents and consequences (pp. 247-282). Hillsdale, NJ: Erlbaum.

Fehr, B., \& Russell, J. A. (1991). The concept of love viewed from a prototype perspective. Journal of Personality and Social Psychology, 60, 425-438.

Fincham, F. D. (1994). Cognition in marriage: Current status and future challenges. Applied and Preventive Psychology: Current Scientific Perspectives, 3, 185-198.

Fincham, F. D. (1998). Child development and marital relations. Child Development, 69, 543-574.

Fincham, F. D., \& Beach, S. R. (1999). Marital conflict: Implications for working with couples. Annual Review of Psychology, 50, 47-77.

Fincham, F. D., Beach, S. R. H., \& Kemp-Fincham, S. I. (1997). Marital quality: A new theoretical perspective. In R. J. Sternberg \& M. Hojjat (Eds.), Satisfaction in close relationships (pp. 275-304). New York: Guilford.

Fincham, F. D., \& Bradbury, T. N. (1987). The assessment of marital quality: A reevaluation. Journal of Marriage and the Family, 49, 797-809.

Fincham, F. D., Garnier, P. C., Gano-Phillips, S., \& Osborne, L. N. (1995). Pre-interaction expectations, marital satisfaction and accessibility: A new look at sentiment override. Journal of Family Psychology, 9, 3-14.

Fincham, F. D., \& Linfield, K. (1997). A new look at marital quality: Can spouses be 
positive and negative about their marriage? Journal of Family Psychology, 11, 489-502.

Fitness, J. (1996). Emotion knowledge structures in close relationships. In G. J. O. Fletcher \& J. Fitness (Eds.), Knowledge structures in close relationships (pp. 195-218). Mahwah, NJ: Erlbaum.

Fletcher, G. J., \& Fincham, F. D. (1991). Attribution processes in close relationships. In G. J. Fletcher \& F. D. Fincham (Ed.), Cognition in close relationships (pp. 7-35). Hillsdale, NJ: Erlbaum.

Fletcher, G. J. O., \& Fitness, J. (1996). Introduction. In G. J. O. Fletcher \& J. Fitness (Eds.), Knowledge structures in close relationships (pp. xi-xv). Mahwah, NJ: Erlbaum.

Forgas, J. P., Levinger, G., \& Moylan, S. J. (1994). Feeling good and feeling close: Affective influences on the perception of intimate relationships. Personal Relationships, 1, 165-184.

Glenn N. D. (1990). Quantitative research on marital quality in the 1980s: A critical review. Journal of Marriage and the Family, 52, 818-831.

Gollwitzer, P. M., \& Bargh, J. A. (1996). The psychology of action: Linking cognition and motivation to behavior. New York: Guilford.

Gottman, J. M. (1994). What predicts divorce? Hillsdale, NJ: Erlbaum.

Gray, J. A. (1987). The psychology of fear and stress. Cambridge: Cambridge University Press.

Hassebrauck, M. (1997). Cognitions of relationship quality: A prototype analysis of their structure and consequences. Personal Relationships, 4, 163-186.

Herr, P. M., Sherman, S. J., \& Fazio, R. H. (1983). On the consequences of priming: Assimilation and contrast effects. Journal of Experimental Social Psychology, 19, 323-340.

Higgins, E. T. (1996). Knowledge activation: Accessibility, applicability, and salience. In E. T. Higgins \& A. W. Kruglanski (Eds.), Social psychology: Handbook of basic principles (pp. 133-168). New York: Guilford Press.

Higgins, E. T. (1997). Beyond pleasure and pain. American Psychologist, 52, 1265-1400.

Hollingshead, A. B. (1998). Retrieval processes in transactive memory systems. Journal of Personality and Social Psychology, 74, 659-671.

Huston, T. L., McHale, S. M., \& Crouther, A. C. (1986). When the honeymoon's over: Changes in the marriage relationship over the first year. In R. Gilmore \& S. Duck (Eds.), The emerging field of personal relationships (pp. 109-132). Hillsdale, NJ: Erlbaum.

Jacobson, N. S. (1985). The role of observation measures in marital therapy outcome research. Behavioral Assessment, 7, 287-308.

Jacobson, N. S., \& Christensen, A. (1996). Integrative couple therapy: Promoting acceptance and change. New York: Norton.

Jacobson, N. S., \& Margolin, G. (1979). Marital therapy: Strategies based on social learning and behavior exchange principles. New York: Brunner/Mazel.

Julien, D., Markman, H. J., Lindahl, K., Johnson, H. M., \& Van Widenfelt, B. (1989). Interactional dimensions coding system coder's manual. Unpublished manuscript, University of Denver.

Karney, B. R., \& Bradbury, T. N. (1995). The longitudinal course of marital quality and stability: A review of theory, method, and research. Psychological Bulletin, 118, 3-34.

Katz, J., \& Beach, S. R. H. (1997). Self-verification and depression in romantic relationships. Journal of Marriage and the Family, 59, 903-914.

Kubovy, M. (1977). Response availability and the apparent spontaneity of numerical choices. Journal of Experimental Psychology: Human Perception and Performance, 3, 359-364.

Lavee, Y., McCubbin, H. I., \& Olson, D. H. (1987). The effect of stressful life events and transitions on family functioning and well-being. Journal of Marriage and the Family, 49, $857-873$.

Locke, H. J., \& Wallace, K. M. (1959). Short marital adjustment prediction tests: Their reliability and validity. Marriage and Family Living, 21, 251-255.

Markus, H., \& Smith, J. (1981). The influence of self-schemata on the perception of others. In N. Cantor \& J. F. Kihlstrom (Eds.), Personality, cognition, and social interaction (pp. 233-262). Hillsdale, NJ: Erlbaum. 
Murray, S. L., Holmes, J. G., \& Griffin, D. W. (1996). The benefits of positive illusions: Idealization and the construction of satisfaction in close relationships. Journal of Personality and Social Psychology, 70, 79-95.

Norton, R. (1983). Measuring marital quality: A critical look at the dependent variable. Journal of Marriage and the Family, 45, 141-151.

O'Mahen, H. A., Beach, S. R. H., \& Tesser, A. (in press). Relationship ecology and negative communication in romantic relationships: A self-evaluation maintenance perspective. Personality and Social Psychology Bulletin.

Raush, H. L., Barry, W. A., Hertel, R. K., \& Swain, M. A. (1974). Communication, conflict, and marriage. San Francisco: Jossey-Bass.

Repetti R. L. (1989). Effects of daily workload on subsequent behavior during marital interaction: The roles of social withdrawal and spousal support. Journal of Personality and Social Psychology, 57, 651-659.

Schwarz, N., \& Bless, H. (1992). Constructing reality and its alternatives: An inclusion/exclusion model of assimilation and contrast effects in social judgment. In L. L. Martin \& A. Tesser (Eds.), The construction of social judgments (pp. 217-245). Hillsdale, NJ: Erlbaum.

Schwarz, N., \& Clore, G. L. (1983). Mood, misattribution, and judgments of well-being: Informative and directive functions on affective states. Journal of Personality and Social Psychology, 45, 513-523.

Schwarz, N., Strack, F., \& Mai, H. P. (1991). Assimilation and contrast effects in part-whole question sequences: A conversation logic analysis. Public Opinion Quarterly, 55, 3-23.

Shaver, P. R., Collins, N., \& Clark, C. L. (1996). Attachment styles and internal working models of self and relationship partners. In G. J. O. Fletcher \& J. Fitness (Eds.), Knowledge structures in close relationships (pp. 25-62). Mahwah, NJ: Erlbaum

Srull, T. K., \& Wyer, R. S. (1979). The role of category accessibility in the interpretation of information about persons. Journal of Personality and Social Psychology, 38, 841-856.

Stuart, R .B. (1980). Helping couples change: A social learning approach to marital therapy. New York: Guilford.

Tesser, A. (1988). Toward a self-evaluation maintenance model of social behavior. In L. Berkowitz (Ed.), Advances in Experimental Social Psychology, 21, 181-227.

Tesser, A., \& Beach, S. R. H. (1998). Life events, relationship quality, and depression: An investigation of judgment discontinuity in vivo. Journal of Personality and Social Psychology, 74, 36-52.

Wegner, D. M. (1987). Transactive memory: A contemporary analysis of the group mind. In B. Mullen \& G. R. Goethals (Eds.), Theories of group behavior (pp. 185-208). New York: Springer-Verlag.

Weiss, R. L.(1980). Strategic behavioral marital therapy: Toward a model for assessment and intervention. In J. P. Vincent (Ed.), Advances in family intervention, assessment and theory (Vol. 1, pp. 229-271). Greenwich, CT: JAI Press.

Weiss, R. L. (1996). DAS causes interaction? Posting 15 April to Association for the Advancement of Behavior Therapy Couples Special Interest Group.Listserve (aabt couples sig@psych1.psy.sunysb.edu). 